\title{
Socio-economic determinants of low birth weight in Bangladesh: A multivariate approach
}

\author{
Selina Khatun and Mahmudur Rahman \\ Institute of Epidemiology, Disease Control and Research, Dhaka, Bangladesh. \\ e-mail:knselina@gmail.com
}

\begin{abstract}
Though the health situation of Bangladesh has improved substantially over the years, the low birth weight (LBW) rate is still pretty high. The principal focus of this study was to ascertain the significant determinants for LBW. One hundred and eight LBW babies were compared with 357 normal birth weight babies. Out of 20 possible risk variables analyzed, 9 were found significant when studied separately. Mother's age, education, occupation, yearly income, gravid status, gestational age at first visit, number of antenatal care visit attended, quality of antenatal care received and pre-delivery body mass index had significantly associated with the incidence of LBW. Using the stepwise logistic regression, mother's age $(\mathrm{p}<0.001)$, education $(\mathrm{p}<0.02)$, number of antenatal care visit attended $(\mathrm{p}<0.001, \mathrm{OR}=29.386)$ and yearly income $(\mathrm{p}<0.001, \mathrm{OR}=3.379)$ created the best model, which predicted $86.1 \%$ and $94.4 \%$ of the LBW babies and normal birth weight babies respectively. Maternal age, educational level and economic status play an important role in the incidence of low birth weight.
\end{abstract}

\section{Introduction}

More than 20 million infants worldwide representing 15.5 percent of all births are born with low birth-weight (LBW), 95.6 percent of them born in developing countries. In Bangladesh, both growth rate and LBW rate are quite high (1.49, $36 \%)^{1}$. Neonatal survival depends on both gestational maturity and birth weight and is not significantly better in babies who are LBW for gestational age ${ }^{2}$. Mortality rates of very low birth weight babies have been shown to be very high in several studies. Findings of a community-based longitudinal study conducted in rural villages during 1993-1994 revealed that $73 \%$ of the 34 infants who died before 12 months of age were the LBW babies ${ }^{3}$.

In addition to its impact on infant mortality, LBW has been associated with higher probabilities of infection, malnutrition and handicapped conditions during childhood (including cerebral palsy), mental deficiencies and problems related to behavior and learning during childhood ${ }^{4,5}$. Children who survive LBW have a higher incidence of diseases, retardation in cognitive development and undernourishment. There is also evidence that LBW or it's determinant factors are associated with a predisposition to higher rates of diabetes, cardiac diseases and other future chronic health problems ${ }^{6,7}$. In developing countries, there are more babies with poorer growth having the risk of more diabetic, hypertensive and coronary heart disease patients. Moreover with the demographic transition through increased life expectancy at birth, these countries are going to face more burdens of chronic diseases.

The biological processes that affect the fetus in utero are related to the mother's physiology, including her nutrition (mother's weight before pregnancy and history of having newborns with LBW), exercise, infections and consumption of tobacco, alcohol and other drugs 8,9 .

During the fetal phase, growth depends on the nutritional condition of the mother, indicating that pregnant women should not only increase their weight but also consume essential nutrients. For many women in the developing world however, economic, social and cultural factors make it difficult for them to obtain the necessary food and health care, which are closely interrelated. Some researchers consider that health, therefore, may be an important determinant of opportunities in life and this process termed 'selection by health', and suggest that health 'selects' people in different social strata ${ }^{10,11}$. 
The socio-economic factors are income, education, occupation, household leadership and gender differences related to roles within the family ${ }^{12,13}$.

In Bangladesh the factors which are considered to affect birth weight are both biological and service related. Among these factors maternal undernutrition, teenage pregnancy, poor antenatal care and nutrition education may play crucial roles in causing LBW. The beneficial effects of prenatal care on pregnancy outcome have been described in many observational studies over several decades. Many studies have demonstrated an association between lack of antenatal care and adverse pregnancy outcomes such as maternal mortality, perinatal mortality, LBW and premature delivery $^{14,15}$. Antenatal care is recognized as an essential element for the screening, primary or secondary prevention and treatment of pregnancy complications.

WHO technical working group committee has been recommended 4 antenatal visits for a woman with normal pregnancy. They have also set the standard of quality antenatal care ${ }^{16}$.

The independent effect of each of the factors for LBW is still debatable. The present study highlightened selected independent factors of LBW through multiple regression analysis and thus would have contributed in reducing the incidence of low birth weight by giving more attention to them.

\section{Materials and Methods}

This study was carried out at Azimpur Maternal and Child Health Training Institute from July 2002 to June 2003. On an average $400-500$ babies are born here in a month.

Samples were selected purposively following the inclusion and exclusion criteria. Inclusion criteria for the baby were as follows: i) live- birth singleton infants, ii) baby born by normal vaginal delivery. Exclusion criteria for the mother were as follows: i) non antenatal care card holders, ii) premature babies, iii) still born babies, iv) pregnant women who had any medical complication (e.g diabetes mellitus, heart disease, chronic lung disease, jaundice etc), v) eclamptic and pre-eclamptic subjects, vi) multiple pregnancies, vii) caesarian section cases. viii) congenital abnormal babies and ix) postmature babies.

Information collected from the mother for socioeconomic characteristics, obstetrical history, intake of iron and vitamins, hyperemesis gravidarum, knowledge on antenatal advice and danger signs of pregnancy through face to face interview by structured interview form. Record review format was used for reviewing antenatal care cards. A spring type weighing scale was used to measure birth weight of the babies just after the delivery.

Each questionnaire was completed within 24 hours of birth.

Number of gravida was recorded as number of conception occurred (whatever was the outcomelive birth, stillbirth, abortion, IUD). Gestational age at first visit in weeks calculated from the record of last menstrual period (L.M.P) and date of first visit by taking the difference between them. Birth to conception interval was estimated as duration in months between the immediate previous birth and conception of current pregnancy as stated by the mother. Body mass index (BMI) is calculated as weight in $\mathrm{kg}$ divided by height in meter ${ }^{2}$. For percentage of tetanus toxoid administered $100 \%$ was taken when 2 doses of tetanus toxoid was recorded, $50 \%$ when 1 dose and $0 \%$ when no dose was recorded. A pilot study of 25 questionnaires was conducted in another nearby public medical college hospital and analyzed to check the feasibility of the study.

A scoring plan was made for the measurement of quality of antenatal care. For each element of the quality item recorded a score of 1 was given if the element was fulfilled and a score of 0 if not. The total score obtained for each quality item was expressed as a percentage of the maximum obtainable score. The level of quality of antenatal care in each visit was measured and an average of these level plus percentage scoring for provision of pregnancy related advice and explaining danger sign to the mother reflected the overall quality of antenatal care. Finally quality of antenatal care was graded as follow:

Mean +1 SD above=Good; Mean \pm 1 SD=Average; Mean $-1 \mathrm{SD}=$ Poor

The following elements of quality of antenatal care were taken into account (whether the activities were recorded or not, the mother was interviewed for her knowledge on antenatal advice and danger sign) to determine the level of quality in each antenatal visit: personal history, previous obstetrical history, present medical history, menstrual history, physical examination, obstetrical examination, hemoglobin measurement, urine analysis for albumin and sugar, tetanus toxoid administered, explaining danger sign to the patient, providing pregnancy related advice to the patient and frequency of antenatal visit.

Quality control of data was done concurrently, daily or day after basis. Cleaning of data, checking for inconsistencies and elimination of errors were 
done before data coding. Data coding and receding were done according to need. After collection, data was checked, verified, cleaned, edited and entered into SPSS program in the computer. Simple descriptive analysis, chi-square test was done to determine the risk factors. Logistic regression analysis ${ }^{17}$ was used to assess relationship between LBW and significant maternal socio-demographic, reproductive and health service related factors. Age was divided into 2 separate groups as $<20$ and $\geq 30$ years as opposed to 20-29 years because extremes of age have been reported to be associated with $\mathrm{LBW}^{18}$.

For the religion as no other religious groups were present there, it was taken as Muslims and Hindus. Education was coded according to the education system of Bangladesh. Family size was classified according to the average family size of Bangladesh, and income as below and average per head annual income as reported in Bangladesh Bureau of Statistics 2003. 1st and $4^{\text {th }}$ or more gravida are in the high risk group for low birth weight, that's why, it was coded into 2 groups ${ }^{19}, 1 \mathrm{st}$ and $\geq 4$ in one group and 2-3 in another.

Birth to conception interval between immediate previous pregnancy and the present should be at least 24 month $^{20}$ depending on this information it was categorized to 2 groups.

Body mass index and number of antenatal visits were grouped according to WHO grading ${ }^{16}$. The multiple logistic regression analysis was performed to give a better indication of the contribution of each of the risk factors to LBW. A case was coded as 1 if it belonged to the category of interest and as 0 if otherwise. Logistic regression results are reported as odds ratio and $95 \%$ confidence interval along with $\mathrm{p}$ value.

\section{Results}

A total of 1,467 births occurred during the study period, of which 465 met the study criteria. Among which 108 were LBW and 357 were normal birth weight (NBW). When Chi-square test was done for individual factors, age, education, occupation, per head yearly income, gravid status of mother, gestational age at Ist visit, pre-delivery BMI, quality of antenatal care received and number of antenatal visits attended were found to be significant. LBW $(\mathrm{N}=108)$ babies mostly come from the mother of $<19$ and $\geq 30$ age group [ 88 $(81.5 \%)]$, without education [66 (66.1\%)], belongs to the family of below average per capita yearly income [9 (85.2\%)] (Table I), 1st and 4th or more gravid those started their antenatal care in the last trimester 23 (Table II), and who attended $<4$ antenatal visit [96 (88.11)] (Table III).

Table I: Effects of maternal socio-economic factors on infant birth weight

\begin{tabular}{|c|c|c|c|}
\hline Variables & $\begin{array}{l}\text { LBW babies } \\
(\mathrm{n}=108)\end{array}$ & $\begin{array}{c}\text { NBW babie } \\
(\mathrm{n}=357)\end{array}$ & $\mathrm{p}$ value \\
\hline \multicolumn{4}{|l|}{$\overline{\text { Age }}$} \\
\hline 20-29 years & 20 & 287 & $\chi 2=141.501 \mathrm{p}<0.001$ \\
\hline$<19$ and $\geq 30$ & 88 & 70 & \\
\hline \multicolumn{4}{|l|}{ Religion } \\
\hline Hindu & 7 & 15 & $\chi 2=0.956, \mathrm{NS}$ \\
\hline Muslim & 101 & 342 & \\
\hline \multicolumn{4}{|l|}{ Residence } \\
\hline Urban & 64 & 236 & NS \\
\hline Rural & 27 & 87 & \\
\hline Suburban & 17 & 34 & \\
\hline \multicolumn{4}{|l|}{ Education } \\
\hline No & 66 & 24 & $\chi 2=180.678, \mathrm{p}<0.001$ \\
\hline $\begin{array}{l}\text { Primary } \\
\text { Secondary and }\end{array}$ & 33 & 94 & \\
\hline above & 9 & 239 & \\
\hline \multicolumn{4}{|l|}{ Occupation } \\
\hline Housewife & 87 & 229 & $\chi 2=10.254, \mathrm{p}<0.01$ \\
\hline Working & 21 & 128 & \\
\hline \multicolumn{4}{|l|}{ Family member } \\
\hline$\leq 5$ & 71 & 247 & NS \\
\hline$>5$ & 37 & 110 & \\
\hline \multicolumn{4}{|c|}{ Family type } \\
\hline Nuclear & 49 & 198 & NS \\
\hline Joint & 59 & 159 & \\
\hline $\begin{array}{l}\text { Yearly income } \\
\text { Below average } \\
\text { per capita income }\end{array}$ & 09 & 135 & $0=74465 n<0001$ \\
\hline $\begin{array}{l}\text { Above average } \\
\text { per capita income }\end{array}$ & 16 & 222 & \\
\hline
\end{tabular}

Table II: Maternal reproductive factors affecting birth weight

\begin{tabular}{|c|c|c|c|}
\hline Variables & $\begin{array}{c}\text { LBW babies } \\
(\mathrm{n}=108)\end{array}$ & $\begin{array}{c}\text { NBW babie: } \\
(\mathrm{n}=357)\end{array}$ & $\mathrm{p}$ value \\
\hline \multicolumn{4}{|l|}{ Gravida } \\
\hline 1 st and $\geq .4$ & 23 & 180 & \multirow[t]{2}{*}{$\chi^{2}=28.592, \mathrm{p}<0.001$} \\
\hline $2-3$ & 85 & 177 & \\
\hline \multicolumn{4}{|c|}{ Birth to conception interval } \\
\hline$\geq 24$ month & 21 & 118 & \multirow[t]{2}{*}{ NS } \\
\hline$\leq 23$ month & 23 & 77 & \\
\hline \multicolumn{4}{|l|}{ Still Birth } \\
\hline No & 43 & 189 & \multirow[t]{2}{*}{ NS } \\
\hline Yes & 1 & 6 & \\
\hline \multicolumn{4}{|c|}{ Death of previous children } \\
\hline No & 44 & 189 & \multirow[t]{2}{*}{ Invalid test } \\
\hline Yes & 0 & 6 & \\
\hline \multicolumn{4}{|l|}{ Abortion } \\
\hline No & 38 & 157 & \multirow[t]{2}{*}{ NS } \\
\hline Yes & 6 & 3.8 & \\
\hline \multicolumn{4}{|c|}{ Gestational age at Ist visit } \\
\hline $1^{\text {st }}$ trimester & 3 & 88 & \multirow[t]{3}{*}{$\chi^{2}=219.054, \mathrm{p}<0.001$} \\
\hline $2^{\text {nd }}$ trimester & 24 & 244 & \\
\hline $3^{\text {rd }}$ trimester & 81 & 25 & \\
\hline \multicolumn{4}{|l|}{ Hyperemesis } \\
\hline No & 107 & 357 & \multirow[t]{2}{*}{ Invalid test } \\
\hline Yes & 1 & 0 & \\
\hline \multicolumn{4}{|c|}{ Had Iron and vitamin } \\
\hline No & 87 & 257 & \multirow[t]{2}{*}{ NS } \\
\hline Yes & 21 & 100 & \\
\hline
\end{tabular}


Table III: Maternal health service related factor affecting birth weight

\begin{tabular}{llll}
\hline Variables & $\begin{array}{c}\text { LBW babies } \\
(\mathrm{n}=108)\end{array}$ & $\begin{array}{l}\text { NBW babies } \\
(\mathrm{n}=357)\end{array}$ & $\mathrm{p}$ value \\
\hline $\begin{array}{l}\text { Quality of antenatal care } \\
\text { Poor }\end{array}$ & 43 & 25 & $\begin{array}{l}\chi^{2}=85.862 \\
\mathrm{p}<0.001\end{array}$ \\
$\begin{array}{l}\text { Average } \\
\text { Good }\end{array}$ & 65 & 255 & \\
$\begin{array}{c}\text { Antenatal visit } \\
<4\end{array}$ & - & 77 & \\
$\geq 4$ & 96 & 31 & $\begin{array}{l}\chi^{2}=268.678 \\
\mathrm{p}<0.001\end{array}$ \\
& 12 & 326 &
\end{tabular}

In contrast, NBW ( $\mathrm{n}==357$ ) babies come from 2029 years old mother [287 (80.4\%)] who were medium and highly educated [239 (66.9\%)], had above average per capita yearly income [222 $(62.2 \%)]$ (Table I), started their antenatal care mostly in the $2^{\text {nd }}$ trimester [244 (68.3\%)] (Table II), had average quality care $[255(71.4 \%)]$ and took more than 4 visits [326 (91.3\%)] (Table III).

Table IV: Maternal anthropological factors affecting birth weight

\begin{tabular}{lccc}
\hline Variables & $\begin{array}{c}\text { LBW babies } \\
(\mathrm{n}=108)\end{array}$ & $\begin{array}{c}\text { NBW babies } \\
(\mathrm{n}=357)\end{array}$ & $\mathrm{p}$ value \\
\hline BMI at first visit & & & \\
$\quad<18.5$ & 12 & 48 & Invalid test \\
$\quad \begin{array}{l}18.5-24.99 \\
25 \text { and above }\end{array}$ & 95 & 309 & \\
$\begin{array}{l}\text { Predelivery BMI } \\
<18.5\end{array}$ & $5(4.6)$ & $5(1.4)$ & $\chi^{2}=6.533$ \\
& & & $\mathrm{p}<0.038$ \\
$18.5-24.99$ & $97(89.8)$ & $313(87.7)$ & \\
25 and above & $6(5.6)$ & $39(10.9)$ & \\
\hline
\end{tabular}

The following variables were found insignificant: mother's religion, family size, family type, birth to conception interval, history of stillbirth, neonatal death, abortion in the last pregnancy, hyperemesis in the present pregnancy and intake of iron and vitamin throughout the pregnancy. $\mathrm{BMI}_{1}(\mathrm{BMI}$ at the time of 1st check up) of the mother and sex of the baby was also found to be insignificant (Table IV).

Multivariate analysis (stepwise logistic) was done by taking LBW as 0 , NBW as 1 and the significant individual factors as covariates (mother's age, education, occupation, yearly income, gravid status, gestational age at first visit, number of antenatal care visit attended, quality of antenatal care received and pre-delivery BMI). Only 4 variables created the best model, the rest had no individual effects. Nagelkerke R square increased from $64 \%$ to $78 \%$ from step 1-4. In Hosmer and Lemeshow test, the mode was a very good fit in each step especially at 4 ; chi-sq test value was 0.848 . The overall classification was also increased from step 1 to step 4 from $90.8 \%$ to $92.5 \%$. Odds ratios were shown in Table V.
Table V: Result of stepwise multiple logistic regression

\begin{tabular}{llc}
\hline Variables & Odds ratios & $\begin{array}{c}95 \% \\
\text { confidence } \\
\text { interval }\end{array}$ \\
\hline $\begin{array}{l}\text { Age of the mother } \\
(0=20-29 \text { years, } 1=<9 \text { and }>30 \text { years })\end{array}$ & 0.162 & $0.070-0.376^{*}$ \\
$\begin{array}{l}\text { Mother's education } \\
(0=\text { otherwise, } 1=\text { no education })\end{array}$ & 0.292 & $0.099-0.863^{* *}$ \\
$\begin{array}{l}\text { Income }(0=\text { above average yearly per } \\
\text { head income, } 1=\text { below average } \\
\text { yearly per head income. }\end{array}$ & 3.379 & $1.255-9.097^{*}$ \\
Antenatal visits $(0>4$ visit, $1<4$ visit $)$ & 29.386 & $12.611-68.479^{*}$ \\
\hline$*=\mathrm{p}<0.001 ; * *=\mathrm{p}<0.02$ & &
\end{tabular}

\section{Discussion}

LBW is a public health problem linked to a wide range of possible predictors, sometimes those are difficult to handle. Despite efforts to decrease the proportion of newborns with LBW, success has been quite limited and the problem persists in both developing and developed countries ${ }^{21}$. There are a number of studies around the world done on this subject by using different methodologies. Either they evaluate the effects of the factors in isolation through cross tabulations or, utilizing statistical techniques to see the individual factors in presence of others. The later is more likely to give a better indication of the contribution to low birth weight of each of the various risk factors. Both ways were followed in this study. Some of the information of this study was collected from the mother by interviewing her and some by reviewing the records. If it could have been possible to cross check the mother's interview answer with that of records, it would have been better enough. It was one of the other limitations of the study. Moreover the study was done in an urban clinic thus, it can not be the true representative of the country picture but, there was in total $114(24.5 \%)$ mothers come from rural area so, they can be a part of the rural scenario.

Most of the mother of LBW babies in this study belonged to the $<19$ and $\geq 30$ years whereas it was 20-29 years for the mother with normal birth weight babies. Thus the maternal age of 20-29 years has found to be the most suitable age group for giving birth to normal weight babies. The finding of the present study is in agreement with many similar studies in developing countries ${ }^{22,23}$. There was insignificant association between residence and birth weight. Because both groups are taking care from the same place so, this insignificant association may happen.

Mother's educational status has great influence on birth weight of the baby. In this study maternal education, income and occupation had significant 
association with birth weight. The findings are similar with some other studies ${ }^{22,23}$. There is statistically insignificant association between family size and birth weight. Begum and Barua ${ }^{24}$ also found similar results.

Whilst younger women are more likely to be primiparous than older women, and conversely, the older women are likely to be of the highest parity, primiparity and multiparity are in some studies independent predictors of LBW. In this study there was no association between primiparity and grand multiparity alone or combined with LBW.

Birth to conception interval has insignificant association with birth weight. One study showed similar findings, "no increased risk of low birth weight for short pregnancy intervals after adequate multivariate control for confounding" ${ }^{25}$. It may happen because it is not only the interval, some more, specially, the nutritional factor responsible for birth weight of baby. If a woman could regain her nutritional status before the conception of baby and could keep it for the period next, it may be possible to get a normal weight baby. The insignificant association between previous pregnancy abortion, stillbirth and neonatal death, hyperemesis in present pregnancy and birth weight in the present study might follow the logic of the above. Only hyperemesis for a very initial stage of pregnancy might not very hazardous for the birth weight of the baby. The relationship of incidence of low birth weight and gestational age at $1^{\text {st }}$ visit was significant. It is similar to the findings of Bener et $\mathrm{al}^{26}$.

The relationship between predelivery BMI and birth weight is consistent with a large number of studies in the west ${ }^{26,27}$ and in developing ${ }^{28}$ and Gulf countries $^{29}$ though most of them used post delivery BMI. But there was negative correlation between maternal BMI at $1^{\text {st }}$ visit and birth weight in this and Osman ${ }^{30}$ study and Ding et $\mathrm{al}^{31}$ study. The time between the 1 st visit and delivery can explain this. Proper nutrition at this time can make things possible. Sex of the baby had insignificant relation with birth weight.

The present study showed the positive effect of number of antenatal care visit on birth weight. Those mothers received 4 or more antenatal care gave birth to higher birth weight babies in comparison to mothers who received less then 4 antenatal care visit. The other studies also found similar result ${ }^{22,32}$. Greenberg ${ }^{32}$ has shown that the strength of association between antenatal care and birth weight varies with different social group and is modified by social situation.
There is only one study done by Nair et $\mathrm{al}^{33}$ to see the dose response relationship between quality of antenatal care and birth weight, in that study quality was scored based on the number of antenatal care visits, place of antenatal care, status of tetanus toxoid immunization and iron and folic acid supplementation, recording of weight and blood pressure during each visit and blood and urine examination.

In Azimpur Maternal and Child Health Training Institute, modified WHO standard is used for antenatal care visits. In this study along with some more variables (details in methodology), all of above mentioned variables were taken except, place of antenatal care, because it was not relevant for this study and number of antenatal care visits were taken as an independent variable.

There are significant relationship found between quality of antenatal care and birth weight in the present and Nair et $\mathrm{al}^{33}$ study.

There is also significant relationship between number of antenatal care visits and birth weight. This finding was consistent with Desjardins et $\mathrm{al}^{34}$ study result. In that study only mother's age, education, income and number of antenatal visit had independent significant effect on birth weight.

In conclusion, this study suggests that there are several factors interplaying which lead to LBW babies. Socio-demographic factors (maternal age, educational level and economic status) and quality of antenatal visit (in terms of contains and number) are more important.

\section{References}

1. State of world children, UNICEF-2004, available at http://www.unicef.org/publications/index.html

2. Crowther ME. A retrospective study of all low birth weight preterm babies born in Bmjr in between 19801989. JR Army MED Corps. 1990; 136: 43-49.

3. Gazi R, Karim F, Ali A. Low birth weight was the major predictor of infant deaths: Evidence from a prospective study in rural Bangladesh. Brac Research Annual report, 2001.

4. Berkowitz GS, Papiemik E. Epidemiology of preterm birth. Epidemiol Rev. 1993; 15: 414-43.

5. Dunin-Wasowicz D, Rowecka-Trzebicka K, Milewska- Bobula B, Kassur-Siemienska B, Bauer A, Idzik M, Lipka B, Marcinski P. Risk factors for cerebral palsy in very low birth weight infants in the 1980s and 1990s. J Child Neurol. 2000; 15: 414-20.

6. Barker DJP, Forsen T, Uutela A, Osmond C, Eriksson JG. Size at birth and resilience to effects of poor living conditions in adult life: Longitudinal study. Br Med J. 2001; 323: 1273-76. 
7. Eriksson JG, Forsen T, Tuomilehto J, Winter PD, Osmond C, Barker DJP. Catch up growth in childhood and death from coronary heart disease: Longitudinal study. Br Med J. 1999; 318: 427-431.

8. Lynch J, Kaplan G. Socio-economic position. In: Social epidemiology. Berkman LF, Kawachi I (eds). Oxford University Press, 2000, pp 13-35.

9. Kramer M. Determinants of low birth weight: Methodological assessment and meta analysis. Bull WHO. 1987; 65: 663-737.

10. Marmot MG, Shipley MJ. Do socio-economic differences in mortality persist after retirement? 25 years follow-up of civil servants from the first Whitehall study. Br Med J. 1996; 313: 1177-80.

11. Wadworth M. Early life. In: Social determinants of health. Marmot M, Wilkinson RG (eds). Oxford University Press, 1999, pp 44-52.

12. Kennedy BP, Kawachi I, Glass R, Prothrow-Stith D. Income distribution, socio-economic status and self rated health in the united states: Multilevel analysis. $\mathrm{Br}$ Med J. 1998; 317: 917-21.

13. Ecob R, Smith GD. Income and health: What is the nature of the relationship? Soc Sci Med. 1999; 48: 693-705.

14. Coria-Soto I, Bobadilla J, Notzon F. The effectiveness of antenatal care in preventing intrauterine growth retardation and low birth weight due to preterm delivery. Int J Qual Health Care 1996; 8: 13-20.

15. Munjanja SP, Lindmark G, Nystrom L. Randomized controlled trial of a reduced-visits program of antenatal care in Harare, Zimbabwe. Lancet 1996; 348: 364-69.

16. WHO publications available at http://www.who.int/reproductivehealth/publications/R HR_01_30/

17. Hosmer DW, Lemmeshow S. Model building strategies and methods for logistic regression: Applied regression. New York, Wiley, 1990, pp 83-134.

18. Behnnan RE. Preventing low birth weight: A pediatric perspective. J Pediatr. 1985; 107: 842-54.

19. Canosa CA. Intrauterine growth retardation in India and Bangladesh 1983. In: Intrauterine growth retardation. Jacqes S (ed). Nestle Nutrition Workshop Series, 1989, pp 183-204.

20. Malik S, Radha G, Udhani R, Waingankar P. Maternal Biosocial factors affecting low birth weight. Indian J Pediatr. 1997; 64: 373-77.

21. Laura P, Torres A, Patricia C, Sergio F, Juan P, villaBarragan, et al. Socio-economic factors and low birth weight in Mexico. BMC Public Health 2005; 5: 20.
22. Naher N, Afroza S, Hossain M. Incidence of LBW in three selected communities of Bangladesh. Bangladesh Med Res Counc Bull. 1998; 24: 49-54.

23. Karim E, Mascie-Taylor CG. The association between birth weight, socio-demographic variables and maternal anthropometry in an urban sample from Dhaka, Bangladesh. Ann Hum Biol. 1997; 24: 387401.

24. Begum R, Barua S. Birth weight in relation to other anthropometric indices and some biological and socioeconomic factors: A study in a city hospital. Bangladesh J Nutr. 1996; 9: 15-18.

25. Papienik E, Kaminski M. Multifactorial study of the risk of prematurity at 32 weeks of gestation: A study of the frequency of 30 predictive characteristics. J Pediatr Med. 1974; 2: 30-36.

26. Bener A, Razzaq A, Dawodu A. Socio-demographic risk factors associated with low birth weight in United Arab Emirates. J Biosoc Sci. 1996; 28: 339-46.

27. Taren DL, Graven SN. The association of prenatal nutrition and educational services with low birth weight rates in a Florida program. Public Health Rep. 1991; 106: 426-36.

28. Viller J, Belizan JM. The relative contribution of prematurity and fetal growth retardation to low birth weight in developing and developed countries. Am J Obstet Gynecol. 1982; 143: 793-98.

29. Youssef A, Ellissa AL, Hassan S, Baaqee L, Khalid N. Low birth weight in Riyadh, Saudi Arabia: Incidence and risk factors. Ann Trop Pediatr. 1991; 11: 75-82.

30. Osman E. Perinatal outcome in an obstetric cohort of Mozambican women. J Trop Pediatr. 2001; 47: 50309.

31. Ding PH, Huong TT, Vuong TH, Bengt H, Lars AP. Maternal factors influencing the occurrence of low birth weight in northern Vietnam. Ann Trop Pediatr. 1996; 16: 327-33.

32. Greenberg RS. The impact of prenatal care in different social groups. Am J Obstet Gynecol. 1983; 145: 797 801 .

33. Nair N, Rao RS, Chandrashekar S, Acharya D, Bhat HB. Socio-demographic and maternal determinants of low birth weight: A multivariate approach. Indian J Pediatr. 2000; 67: 9-14.

34. Desjardins E, Hardwick D. How many visits by health professionals are needed to make a difference in LBW? A dose-response study of the Toronto healthiest babies possible program. Can J Public Health 1999; 90: 224-28. 